\title{
Mutation des horloges biologiques : une grande découverte
}

L'existence d'horloges biologiques est attestée par la chronologie. rigoureuse du développement des organismes, de l'apparition de phénomènes tels que la puberté et la ménopause, et probablement par la détermination génétique de la longévité. Il semblait cependant jusqu'alors bien difficile de donner une base moléculaire à cette notion aux contours un peu métaphysiques. Heureusement, génie des biologistes modernes, la drosophile vint.

Il y a quinze ans environ une équipe américaine parvint à définir un locus génétique dont les mutations modifiaient profondément les rythmes biologiques, dénommé de ce fait "period" (abréviation : "per "). Une première mutation à ce locus abolit toute périodicité comportementale; le mutant est insomniaque et les mâles mutés ont un " chant nuptial " qui a complètement perdu sa périodicité de 60 secondes. D'autres mutants "per", à rythmes allongés ou ralentis, furent par la suite isolés.

A l'avènement des techniques des recombinants d'ADN il devint pos- sible d'isoler un fragment d'ADN de 7,I kilobases portant l'information "per". Les mutants sans rythme biologique n'ont pas d'ARN codés par le locus et les mutants avec un rythme raccourci en ont une quantité accrue. Le transfert d'un gène normal dans la mouche arythmique restaure totalement la périodicité comportementale [I]. La création d'animaux transgéniques " mosaïques ", c'est-à-dire formés de plusieurs types de cellules, permit de démontrer que le fonctionnement normal du locus "per" dans les cellules de la tête, restaurait le rythme circadien, alors que son fonctionnement dans les cellules du thorax normalisait la rythmicité du "chant nuptial". Le produit du gène "per " comporte de longues répétitions de deux aminoacides, sérine-glycine ou thréonineglycine; de semblables répétitions sont détectées chez des vertébrés [2], hommes et souris notamment. Il n'est cependant à ce jour pas possible d'affirmer que ces substances jouent chez les vertébrés un rôle d'horloge biologique. Au point de vue structure d'ensemble, les peptides pouvant être codés par le gène "per" ressemblent un peu aux protéoglycanes, qui sont des glycoprotéines situées à l'extérieur des membranes cellulaires [3].

Ainsi, quoique les mécanismes par lesquels le gène "per " et ses produits jouent un rôle d'horloge biologique restent tout à fait inconnus, l'ensemble des travaux résumés dans cette note constitue la première avancée dans la caractérisation moléculaire des phénomènes de régulation chronologiquement programmée. S'il est vrai que ces fonctions sont conservées au cours de l'évolution des espèces, la génétique formelle de la mouche sera là encore à l'origine d'une formidable avancée de la biologie.

A. $\mathbf{K}$.

1. Zehring WA, Wheeler DA, Reddy $P$, et al. $P$ element transformation with period locus DNA restores rhythmicity to mutant arhythmic Drósophila melanogaster. Cell 1984; 39: 369-76. 2. Shin HS, Bargiello TA, Clark BT, et al. An unusual coding sequence from a Drosophila clock gene is conserved in vertebrates. Nature 1985; $317 ; 445^{-8}$.

3. Kolata G. Genes and biological clocks. Science I985; 230: $115^{1-2}$.

\section{Des plantes transgéniques}

Comme nous le rapportons dans la nouvelle qui suit, l'introduction de gènes étrangers dans des végétaux est maintenant aisément réalisée dans le cas des dicotylédones (pommes de terre, tabac, pétunias, tomates).

Des premiers résultats d'un intérêt économique potentiel ont été obtenus par différents laboratoires qui ont transféré un gène de résistance à un herbicide, le glyphosate, dans différentes plantes. Le groupe Calgène (Cal, USA) a ainsi transformé des plants de tabac par le gène de l'enzyme EPSP synthase, cible du glyphosate; il s'agissait dans ce cas d'un gène bactérien qui donnait une enzyme cytoplasmique, alors que l'EPSP synthase végétale est localisée dans les chloroplastes, ce qui explique peut-être que les plantes transgéniques obtenues n'aient été que partiellement résistantes à l'herbicide. Un groupe de Monsanto Company a pour sa part utilisé le propre gène EPSP synthase des végétaux et l'a placé sous le contrôle d'un promoteur viral fort qui en augmente la transcription de 20 à 40 fois. Les pétunias transgéniques transformés avec le gène hybride ont une activité enzymatique très augmentée dans leurs chloroplastes, et sont résistants au glyphosate. Le transfert de gène dans les monocotylédones, groupe qui inclut les céréales, reste aujourd'hui extrêmement difficile, car le système de l'infection par le plasmide dAgrobacterium tumefa- ciens qui est utilisé pour les dicotylédones n'y est pas utilisable. Des succès préliminaires ont néanmoins été très récemment obtenus dans le transfert d'ADN dans des protoplastes de mais. Un protoplaste est une cellule "dénudée ", débarrassée de sa membrane, et le problème est qu'on ne sait pas encore reconstituer la plante entière à partir d'une telle cellule.

Ainsi la progression dans le domaine des organismes transgéniques, animaux et plantes, constitue-t-elle l'un des aspects les plus spectaculaires $d u$ "génie génétique" moderne.

A. $\mathbf{K}$.

I. Marx JL. Plant gene transfer becomes a fertile field. Science 1985; 230: $1148-50$. 